\title{
Effects of the Jendrassik manoeuvre on muscle spindle activity in man $^{1}$
}

\author{
K-E. HAGBARTH, G. WALLIN, D. BURKE, ${ }^{2}$ AND L. LÖFSTEDT \\ From the Department of Clinical Neurophysiology, University Hospital, Uppsala, Sweden
}

SYNOPSIS Twenty-eight mechanoreceptive units identified as primary or secondary spindle afferents were sampled from muscle nerve fascicles in the median, peroneal, and tibial nerves of healthy adult subjects. The responses of these units to sustained passive muscle stretch, to passive stretching movements, to tendon taps, and electrically-induced muscle twitches were studied while the subject performed repeated Jendrassik manoeuvres involving strong voluntary contractions in distant muscle groups. The manoeuvres had no effect upon the afferent spindle discharges as long as there were no EMG signs of unintentional contractions occurring in the receptor-bearing muscle and no mechanotransducer signs of unintentional positional changes altering the load on that muscle. Unintentional contractions in the receptor-bearing muscle frequently occurred during the manoeuvres, however, and then coactivation of the spindle afferents was observed. Multiunit afferent responses to Achilles tendon taps, led off from tibial nerve fascicles, were in a similar way uninfluenced by the Jendrassik manoeuvres, even when these resulted in marked reinforcement of the calf muscle tendon jerk. The results provide no evidence for fusimotor sensitization of spindles in muscles remaining relaxed during the Jendrassik manoeuvre, and reflex reinforcement occurring without concomitant signs of active tension rise in the muscles tested is presumed to depend upon altered processing of the afferent volleys within the cord.

In the initial study dealing with recordings from muscle spindle afferent nerve fibres in man, Hagbarth and Vallbo (1968) noted a marked enhancement of the activity in these fibres during voluntary isometric contraction of the leg or arm muscles in which the receptors were located. These findings have been verified in many subsequent studies and evidence has accumulated in favour of the suggestion that voluntary movements in man are organized according to the principle of alpha-gamma coactivation, the fusimotor drive being directed to the same muscle or muscle portion as the skeletomotor outflow and being powerful enough to overcome the spindle unloading effect of the contraction in surrounding extrafusal fibres (Vallbo, 1970b, 1971, 1974; Hagbarth et al., 1970b, 1975a).

\footnotetext{
1 The investigation was supported by the Swedish Medical Research Council (Project no. B75-04X-2881-06A).

2 C. J. Martin Research Fellow of the National Health and Medical Research Council of Australia.

(Accepted 7 May 1975.)
}

As long as the receptor-bearing muscles remained relaxed, the Swedish investigators found in awake human subjects no evidence for varying fusimotor tonus-that is, the dynamic and static spindle responses to passive stretch were not appreciably influenced by the Jendrassik manoeuvre (Hagbarth and Vallbo, 1968) or by changes in the attentive state of the subject (Vallbo, 1972), and no reduction in afferent stretch responses was seen after lidocaine blocks of the muscle nerve proximal to the recording site (Hagbarth et al., 1970b, 1975a; Wallin et al., 1973).

Diverging results were recently reported by Burg et al. $(1973,1974)$ who during the Jendrassik manoeuvre found an acceleration of spindle afferent activity in remote relaxed muscles and an irregular spontaneous spindle discharge which varied in frequency with the subject's degree of attention. These findings seem to imply that in awake human subjects intrafusal fibres are exposed to a sustained fusimotor outflow varying 
in strength during various manoeuvres without concurrent changes in the skeletomotor outflow to the receptor-bearing muscles.

The intraneural recording technique provides means of analysing fusimotor system dysfunctions in various motor disorders, but such pathophysiological studies must be based on firmly established data concerning fusimotor system involvement in normal movements. Thus, a reinvestigation was made to check whether the findings of Burg et al. (1974) could be verified and accepted as valid evidence that in healthy subjects the fusimotor system may act diffusely to produce a widespread increase in receptor sensitivity in muscles in which the extrafusal fibres are 'at rest'.

\section{MATERIAL AND METHODS}

Data were obtained from 21 experiments in 18 subjects aged $25-48$ years with no evidence of neurological disease.

MULTI- AND SINGLE-FIBRE RECORDINGS Neural activity was recorded with tungsten microelectrodes inserted manually through the skin into appropriate muscle nerve fascicles. Details of the recording procedure, of the storage and display systems and of amplifiers, filters and noise reducing circuits have been described previously (Hagbarth et al., 1970a, 1975a). Recordings were made from muscle nerve fascicles of the median nerve at the elbow level innervating the long finger flexor muscles (four experiments), fascicles of the tibial nerve in the popliteal fossa innervating triceps surae (seven experiments) and fascicles of the peroneal nerve at the level of the fibular head innervating the anterior tibial and peroneal muscles (10 experiments). The ways of assessing that the electrode had impaled a pure muscle nerve fascicle have been described elsewhere (Hagbarth et al., 1975a), a main criterion being the multiunit afferent discharges appearing in response to passive muscle stretch and tendon taps with concurrent lack of afferent responses to skin strokings and other superficial cutaneous stimuli. In 11 experiments a mean voltage integrator (time constant $0.05-0.1 \mathrm{~s})$ served to give a quantitative measure of the multiunit stretch- and tap responses during the reinforcement tests. Within the muscle nerve fascicles explored, the discharges of individual mechanoreceptive fibres could often be discerned, and as judged by their receptive characteristics the units sampled in this way were classified as group Ia, group Ib, and group II muscle afferent fibres (see below). The effects of remote muscle contractions were studied on 30 identified muscle afferent fibres. An instantaneous frequency meter of similar type to that described by Green (1967) was used in the analysis of the single unit data. In some experiments the output of the instantaneous frequency meter was fed into an RC low pass filter of time constant $0.5 \mathrm{~s}$ in order to smooth out the variability in the frequency plot and produce a continuous line representing mean frequency.

JOINT ANGLE, TORQUE, AND EMG RECORDINGS In experiments on the median nerve the subject was seated with the arm outstretched, the hand supported and the fingers fixed to the rotating plate of a hydraulic device with which controlled passive stretch of the finger flexor muscles could be performed in steps of variable speed and amplitude. In experiments on the tibial and peroneal nerves the subject was lying on one side with the knee extended and the foot fixed to the rotating plate of the hydraulic device. A potentiometer on the pivot of the rotating plate measured the angle of the metacarpophalangeal and ankle joints. A strain gauge bridge mounted on the rotating plate measured changes in torque, the sensitivity of the bridge being adjusted in such a way that small changes in torque down to $0.05 \mathrm{Nm}$ could be readily discerned. Further details are given by Hagbarth et al. (1975a). The electromyogram (EMG) of the receptor-bearing muscles was recorded occasionally with surface electrodes, but usually with a pair of tungsten needle electrodes insulated to within $5 \mathrm{~mm}$ of the tip. Care was taken to ensure that as far as possible the EMG activity thus recorded came from the receptor-bearing muscle. During replay and analysis the direct EMG signals were displayed usually at gains of $500 \mu \mathrm{V} / \mathrm{cm}$ or $200 \mu \mathrm{V} / \mathrm{cm}$. In most experiments, the EMG activity was monitored on a loudspeaker and integrated using a mean voltage 'integrator' of time constant $0.1-0.2 \mathrm{~s}$. These measures aided identification of low amplitude distant potentials which were difficult to distinguish from background noise in the direct recording.

REINFORCEMENT MANOEUVRES The reinforcement manoeuvre used to test the effects of remote muscle contraction consisted of either firm clenching of one fist or the classical Jendrassik manoeuvre, involving forced separation of interlocked clenched hands. In experiments on the median nerve, only the former manoeuvre was performed, using the free hand. No differences were found between these manoeuvres and, hereafter, both are referred to as the 'Jendrassik manoeuvre'. The time course of the manoeuvre was usually determined from EMG recordings obtained 
TABLE 1

NUMBER OF JENDRASSIK MANOEUVRES

\begin{tabular}{|c|c|c|}
\hline Testing conditions & $\begin{array}{c}\text { Manoeuvres } \\
\text { (no.) }\end{array}$ & $\begin{array}{c}\text { Afferent fibres } \\
\text { (no.) }\end{array}$ \\
\hline \multicolumn{3}{|l|}{$\begin{array}{l}\text { 1. At constant length } \\
\text { Definite spindle }\end{array}$} \\
\hline Ia & 25 & 8 \\
\hline II & 26 & 6 \\
\hline \multicolumn{3}{|l|}{ Probable spindle } \\
\hline Ia & 12 & 6 \\
\hline II & 2 & 1 \\
\hline \multicolumn{3}{|l|}{ Tendon organ } \\
\hline Ib & 5 & 1 \\
\hline \multicolumn{3}{|l|}{$\begin{array}{l}\text { 2. During passive stretch } \\
\text { Definite spindle }\end{array}$} \\
\hline Ia & 30 & 10 \\
\hline II & 4 & 3 \\
\hline \multicolumn{3}{|l|}{ Probable spindle } \\
\hline $\begin{array}{l}\text { Ia } \\
\text { Tendon organ }\end{array}$ & 2 & 2 \\
\hline $\begin{array}{l}\text { Tendon organ } \\
\text { Ib }\end{array}$ & & \\
\hline & 2 \\
\hline Definite spindle & & \\
\hline Ia & 19 & 5 \\
\hline \multicolumn{3}{|l|}{$\begin{array}{l}\text { 4. During tendon jerks } \\
\text { Definite spindle }\end{array}$} \\
\hline $\begin{array}{l}\text { Definite spindle } \\
\text { Ia }\end{array}$ & & \\
\hline Ia & 5 & 2 \\
\hline II & 2 & 1 \\
\hline
\end{tabular}

with surface electrodes over the forearm flexor muscle group. Subjects were instructed to remain relaxed in all muscles other than those taking part in the manoeuvre. Compliance with this request was checked for the receptor-bearing muscles by the recordings of EMG and torque described earlier.

UNIT CLASSIFICATION AND TESTING OF REINFORCEMENT EFFECTS Of the 30 mechanoreceptive units analysed in the present study, 28 fulfilled the criteria of muscle spindle afferent fibres as described by Vallbo (1970a). Of these 28 fibres, 18 were also tested using electrically-induced muscle twitches or mechanically-induced tendon jerks, and on the basis of their discharge during the relaxation phase of the twitch they were classified as 'definite spindle afferents', whereas the other 10 units were denoted as 'probable spindle afferents'. The electricallyinduced twitches were usually delivered through needle EMG electrodes, but in a few experiments the stimulus was delivered through the microelectrode which was then switched for recording (blocking time approximately $10 \mathrm{~ms}$, cf. Fig. 7). Depending on their regularity of discharge and their sensitivity to the velocity of stretching movements, spindle afferent fibres were further classified as probably group Ia (21 fibres) or probably group II (seven fibres), although a clear distinction was sometimes difficult. Two afferent fibres were regarded as group Ib afferent fibres from Golgi tendon organs on the basis of their discharge during the rising phase of electrically-induced muscle twitches.

The single unit responses to reinforcement manoeuvres were assessed under four testing conditions designed to detect changes in dynamic and static properties. The manoeuvres were performed with the receptor-bearing muscles maintained at constant length, during controlled stretching movements, during tendon taps, and during electrically-induced muscle twitches. In experiments on the tibial nerve, the effects of reinforcement on the afferent volley produced by percussion of the Achilles tendon were studied. These experiments allowed correlation of the afferent volley with the resulting reflex contraction at measured levels of percussion force.

Each afferent fibre was usually subjected to a number of Jendrassik manoeuvres, but not to all of the four testing conditions. Table 1 shows the numbers of Jendrassik manoeuvres and the numbers of single afferent fibres tested under each of the four testing conditions. Altogether, 127 manoeuvres have been performed on the 28 spindle afferent fibres.

\section{RESULTS}

SPINDLE RECEPTOR SENSITIVITY The 28 spindle afferent fibres had a wide spectrum of receptor sensitivity to active or passive displacement. At seemingly constant muscle length, some fibres maintained a relatively stable, mean discharge frequency, but others proved extremely sensitive to minor disturbances, a sensitivity which made it crucial that equally sensitive measures be used to monitor possible disturbing forces. Examples of this high sensitivity are shown in Fig. 1 for two group Ia fibres. In A, the illustration on the left shows a pronounced afferent discharge in response to stretching at a rate and amplitude which were just above the subject's threshold for perception. The illustration on the right shows spindle acceleration due to fusimotor activation occurring in weak isometric contractions, and high sensitivity to the small internal length changes that occur on relaxation after an isometric contraction (cf. Vallbo, 1970b). In Fig. 1B the frequency plot of another group Ia fibre contains slow periodic irregularities that correspond closely to the respiratory oscillations which became visible in the torque recording only when displayed at high gain. Indeed, on conversion of the frequency plot into a continuous line plot (middle trace), an almost perfect mirror image of the torque 

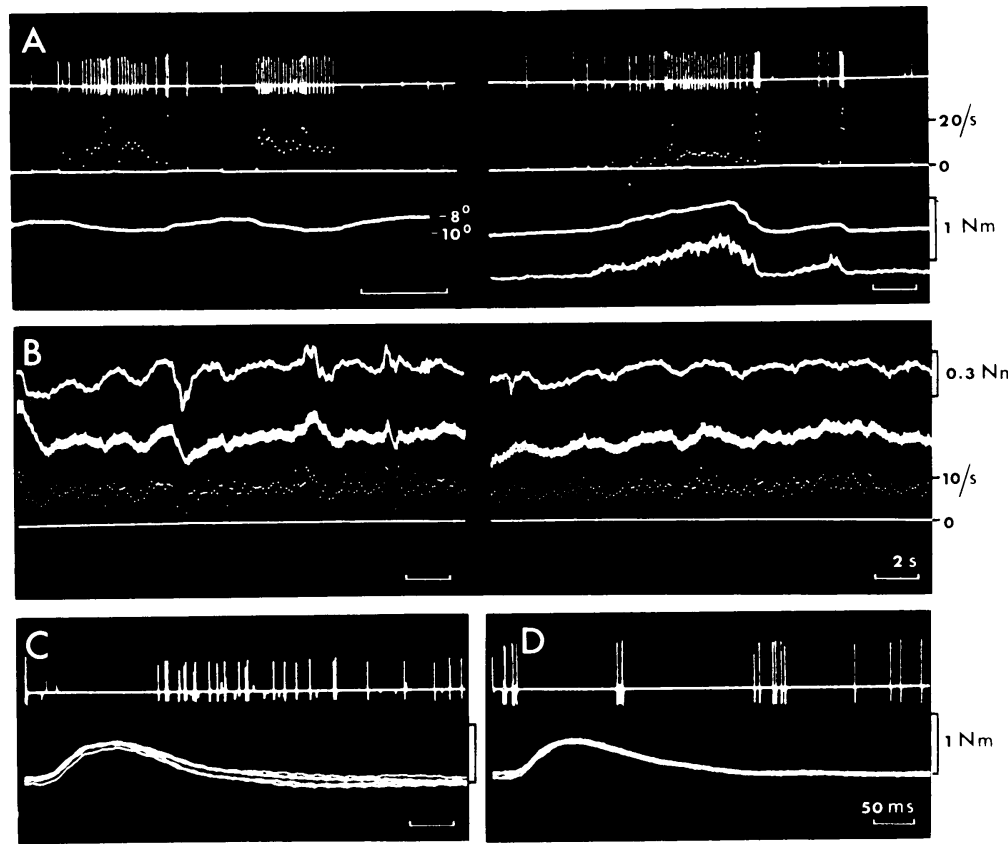

FIG. 1 Muscle spindle sensitivity. A: responses to stretching movements of small amplitude (left) and to weak isometric calf muscle contractions (right) of a gastrocnemius group Ia fibre (twitch test in C). On the left stretching movements of less than 2 (lower trace) evoke a prominent spindle discharge visible in the neurogram (upper trace) and the instantaneous frequency plot (middle trace). As in subsequent Figures, passive stretch of the receptor-bearing muscle is indicated by a downward deflection of the goniometer record. On the right a weak voluntary contraction recorded in the torque signal (third trace) and the integrated gastrocnemius EMG (lowest trace) provokes an increased spindle discharge. Relaxation after the contraction produces a brief high frequency burst of impulses. A similar sequence is seen in the subsequent much weaker unintentional contraction. B: both illustrations are from a tibialis anterior group Ia afferent fibre (twitch test in D) with subject at rest and muscle at constant length. Slow periodic fluctuations are seen in the frequency plot (lowest trace) closely parallelling the respiratory oscillations recorded at high gain in the torque signal (upper trace). In the middle trace the output of the frequency meter was smoothed to give a continuous line plot, thus highlighting the similarity of the irregularities in torque and frequency. C and D: twitch tests of the fibres in $\mathrm{A}$ and $\mathrm{B}$ respectively showing torque (lower traces) and neurogram (upper traces). In each case five sweeps have been superimposed. Neural silence during the rising phase of the contraction and discharge on the relaxation phase identify the units as spindle afferent fibres. In D the very early neural spike probably. represents direct stimulation of the fibre.

record is obtained, allowing for the phase lag introduced by the conversion.

EFFECTS OF REINFORCEMENT ON SINGLE AFFERENT FIBRES Table 2 details the number of muscle nerve afferent fibres that were not influenced by the Jendrassik manoeuvre, and, for those that were influenced, the accompanying changes in the EMG and torque records. In 15 afferent fibres the reinforcement manoeuvre had no effect on the discharge frequency, whether the manoeuvre was performed with the receptor-bearing muscle at constant length (Fig. 2A, B), or performed during controlled muscle stretch (Fig. 2C), during electrically-induced twitches (Fig. 2D) or during tendon percussion. In the remaining 15 fibres changes in discharge fre- quency were observed during reinforcement manoeuvres. However, the responses of most of these fibres were not reproducible (see Table 2 ). The variability of response from one test to the next was especially pronounced for those afferent fibres which exhibited the extreme sensitivity to displacement referred to above. In three fibres the reinforcement led to a decrease in frequency in some tests. Only four spindle afferent fibres increased their discharge frequency in every reinforcement manoeuvre with which they were tested. In all cases, however, where a change of discharge frequency occurred during the Jendrassik manoeuvres, simultaneous contractions or changes in the load on the receptor-bearing muscles were detected (see Table 2). Furthermore, the degree and direction 
TABLE 2

EFFECTS OF JENDRASSIK MANOEUVRES

\begin{tabular}{|c|c|c|c|c|c|c|c|c|}
\hline \multirow[t]{2}{*}{ Unit classification } & \multirow[t]{2}{*}{ Nerve } & \multirow[t]{2}{*}{ Units (no.) } & \multirow{2}{*}{$\begin{array}{l}\text { Uninfluenced } \\
\text { (no.) }\end{array}$} & \multicolumn{5}{|c|}{ Influenced } \\
\hline & & & & Number & Type of & ange & $E M G \pm$ Torque & Torque only \\
\hline \multicolumn{9}{|l|}{ 1. Definite spindle } \\
\hline \multirow{4}{*}{ lat } & & & & & + & (2) & 1 & 1 \\
\hline & Peroneal & 9 & 2 & 7\{ & $0,+$ & (4) & & 4 \\
\hline & Tibial & 1 & , & 28 & + & (1) & 1 & \\
\hline & Iloblal & 4 & - & -\{ & - & (1) & & 1 \\
\hline II & Peroneal & 4 & 2 & 2 & $0,+$ & (2) & 1 & 1 \\
\hline \multirow{4}{*}{$\begin{array}{l}\text { 2. Probable spindle } \\
\text { lat }\end{array}$} & Tibial & 2 & 2 & 0 & & & & \\
\hline & Peroneal & 2 & 2 & 0 & & & & \\
\hline & Tibial & 2 & 2 & 0 & & & & \\
\hline & Median & 4 & 2 & 2\{ & + & (1) & & 1 \\
\hline \multirow{5}{*}{$\begin{array}{l}\text { II } \\
\text { 3. Tendon organ } \\
\text { Ih }\end{array}$} & Peroneal & 1 & () & 1 & $0,+$ & (1) & 1 & \\
\hline & & & & & & (1) & & 1 \\
\hline & Peroneal & 1 & 1 & () & & & & \\
\hline & Median & 1 & 0 & 1 & + & (1) & 1 & \\
\hline & & 30 & 15 & 15 & & (15) & 5 & 10) \\
\hline
\end{tabular}

The symbols,,+- 0 indicate an increase, a decrease, or no change in frequency. Nine fibres gave variable responses to different manoeuvres. The figures in parentheses indicate the number of fibres which gave each particular response. The columns 'EMG \pm Torque ' and 'Torque only' indicate whether those fibres which changed frequency did so with detectable EMG in the receptor-bearing muscle, or with torque changes in the absence of recordable EMG.
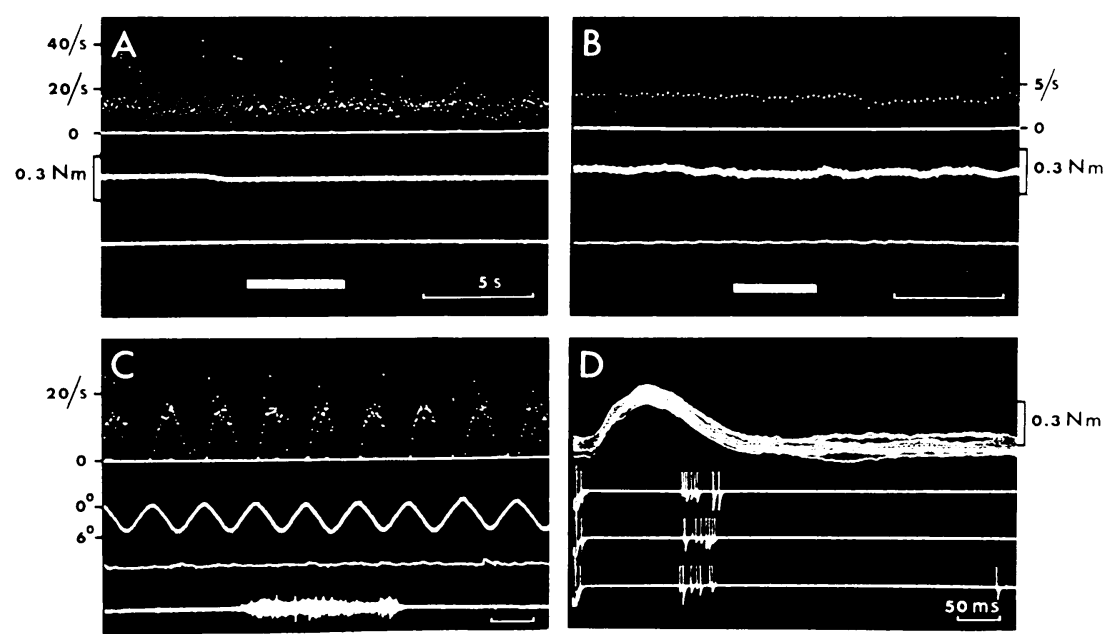

FIG. 2 Lack of effect of reinforcement. A and B represent respectively. a finger Hexor group Ia fibre and a gastrocnemius group II fibre, with muscles maintained at constant length. Traces are, from above, frequency, torque, integrated EMG. Time course of the reinforcement manoeutre is indicated by the solid har. In A a deflection in torque preceded the actual manocurre, but corresponded with the subject's preparation for the manoeuvre. C: response of a tibialis anterior group Ia afferent fibre during passive stretch. Traces are, from above, frequency, joint position, integrated EMG, finger flexor EMG (reinforcement marker). D: a peroneus muscle group Ia afferent fibre discharging during the relaxation phases of electrically-induced peroneus muscle twitches. The torque changes produced $b_{y} 12$ twitches at $1 / \mathrm{s}$ have been superimposed in the upper trace. The neural response's elicited by the first four twitches are superimposed in the second trace, those by the next four twitches in the third trace, and those by the last four witches in the lowest trace. A Jendrassik manoeuvre was performed during twitches 5-8 (third trace); twitches $1-4$ and 9-12 (second and lowest traces) serving as controls. During reinforcement there is no increase in number of potentials, and the potentials do not occur earlier in the relaxation phase. 

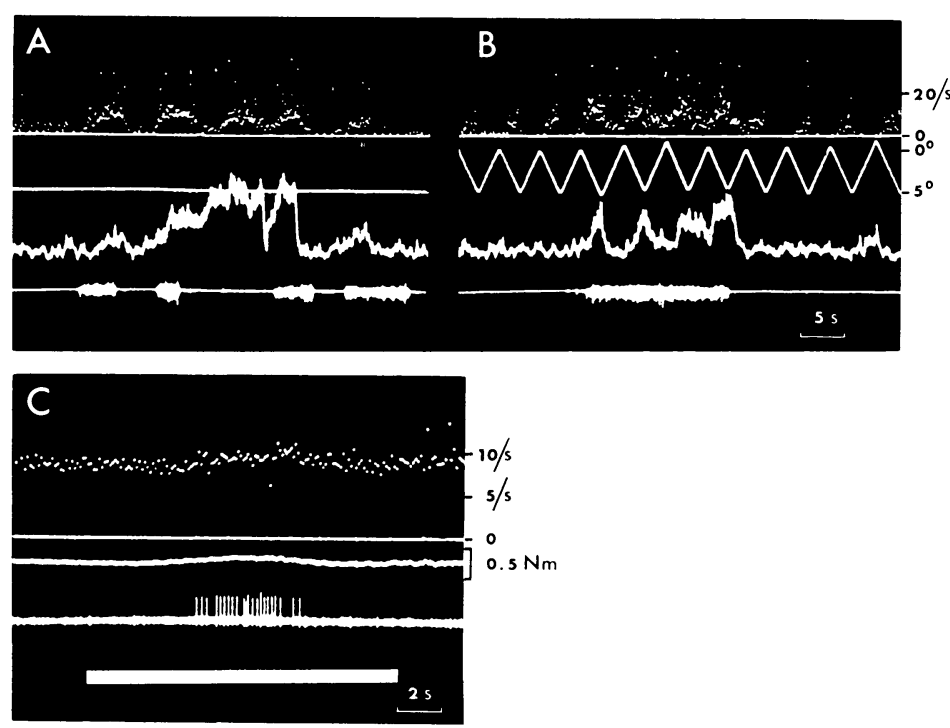
charge of a tibialis anterior group II fibre increased slightly during a Jendrassik manoeuvre (indicated by the solid bar) but this was correlated with a slight increase in torque (second trace) and the appearance of EMG potentials from a single motor unit in tibialis anterior muscle (third trace).
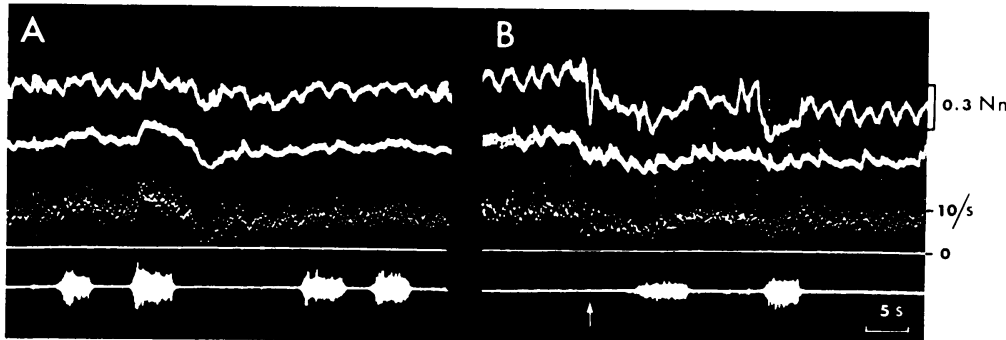

FIG. 4 Changes in spindle discharge correlated with torque changes. Tibialis anterior group Ia afferent fibre with muscle at constant length (same unit as in Fig. IB and D). Traces are from above, torque, smoothed frequency (as in Fig. IB), frequency, and EMG of finger flexor muscles (reinforcement mar-

ker). In A, one Jendrassik manoeuvre of four is associated with a significant increase in discharge frequency but this is correlated with an increase in torque. The unit almost ceases firing when torque falls at the end of the manoeuvre. In $\mathrm{B}$, discharge frequency decreases in two manoeuvres, in parallel with torque. Prominent changes in torque and frequency, indicated by the arrow, occur before the first manoeuvre as the subject prepared for it.

of the changes in firing frequency could always be correlated with the degree and direction of the changes in the extrafusal muscle.

In the manoeuvres where a spindle response was accompanied by EMG activity in the receptor-bearing muscle, the increase in fibre frequency was better correlated with the time course of the EMG events than with the duration of the manoeuvre (Fig. 3). The necessity for careful monitoring of EMG is exemplified by the recordings in Fig. 3. The EMG potentials in $\mathrm{A}$ and $\mathrm{B}$ were visible in the direct EMG recording only as a slight thickening of the background noise level, although their presence was more obvious when monitored on a loudspeaker and displayed at high gain after integration (as in the Figure). In $\mathrm{C}$ the extrafusal contraction was weak, as seen in the torque and EMG records. Indeed, the needle EMG electrodes recorded potentials from only one motor unit 

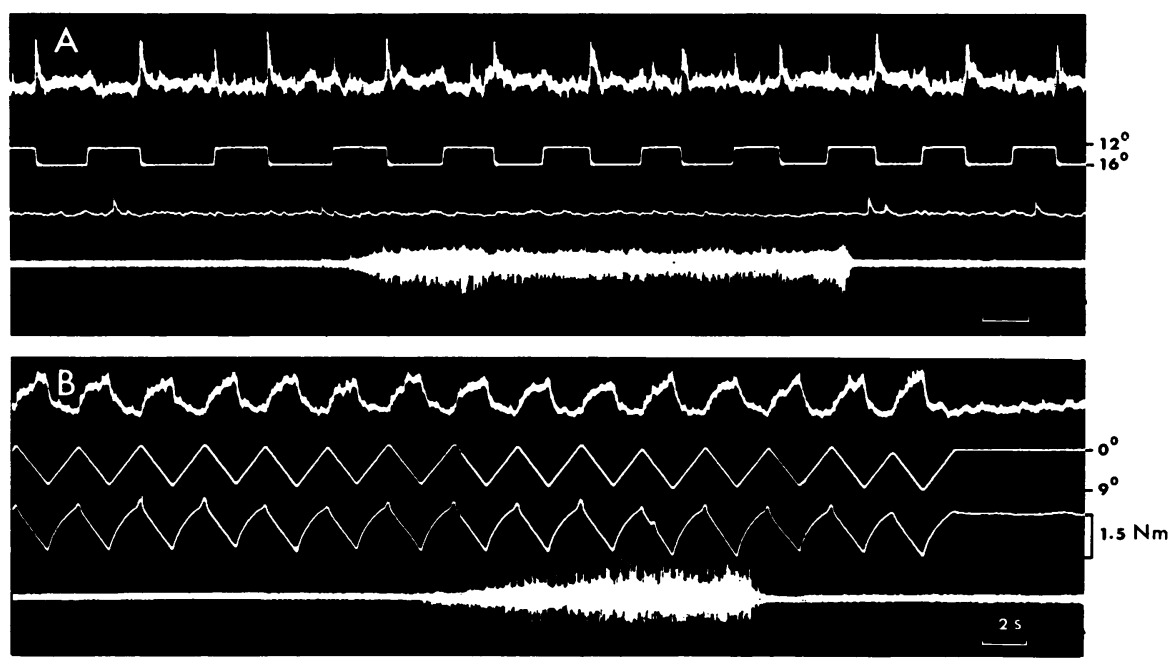

FIG. 5 Lack of effect of reinforcement on multiunit intrafascicular responses to stretch. Integrated multiunit afferent activity (upper trace) in response to stretch at $60^{\circ} / \mathrm{s}$ (A) and $7.5^{\circ} \mathrm{s}(\mathrm{B})$ from fascicles in the peroneal nerve supplying the anterior tibial muscle. Joint position is seen in the second trace; third trace is integrated EMG in $\mathrm{A}$ and torque in $\mathrm{B}$. The reinforcement manoeuvre is indicated by finger flexor EMG (lowest trace).

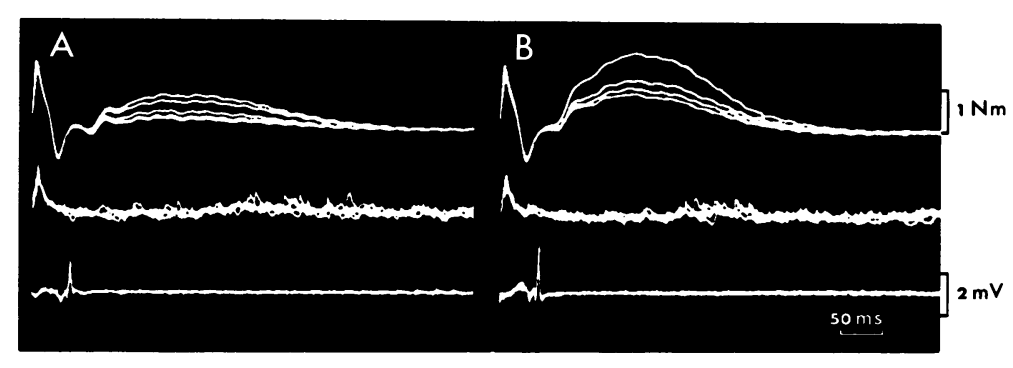

FIG. 6 Integrated neural response recorded from a tibial nerve fascicle to gastrocnemius during percussion of Achilles tendon. Five control tendon taps superimposed in $\mathrm{A}$ and five during a Jendrassik manoeuvre in B. Upper trace: torque changes produced by percussion and by reflex contraction. Middle trace: integrated neurogram, showing the afferent response to percussion, a small reflex efferent neural volley (only visible in B), and asynchronous afferent activity during relaxation of the reflex contraction. In both $\mathrm{A}$ and $\mathrm{B}$ the middle trace has been delayed by $5 \mathrm{~ms}$ relative to the upper and lower traces so that the early afferent volley can be seen clearly. Lower trace: gastrocnemius EMG. Reinforcement results in a larger reflex contraction (EMG and torque) for a constant percussion force. The afferent volley produced by percussion is not increased.

and, although more units were probably active, the coactivation may not have been recognized had surface electrodes been used and torque measurements not been available.

In those manoeuvres where a spindle response occurred without detectable EMG activity the changes in discharge frequency could be correlated with changes in torque. With some of these manoeuvres the torque changes may have been due to active contraction of the receptorbearing muscles not detected since the EMG electrodes were not appropriately positioned to record the potentials of the contracting muscle portions. However, in other manoeuvres (Fig. 4), the frequency changes were due to passive changes in the receptor-bearing muscles result- 

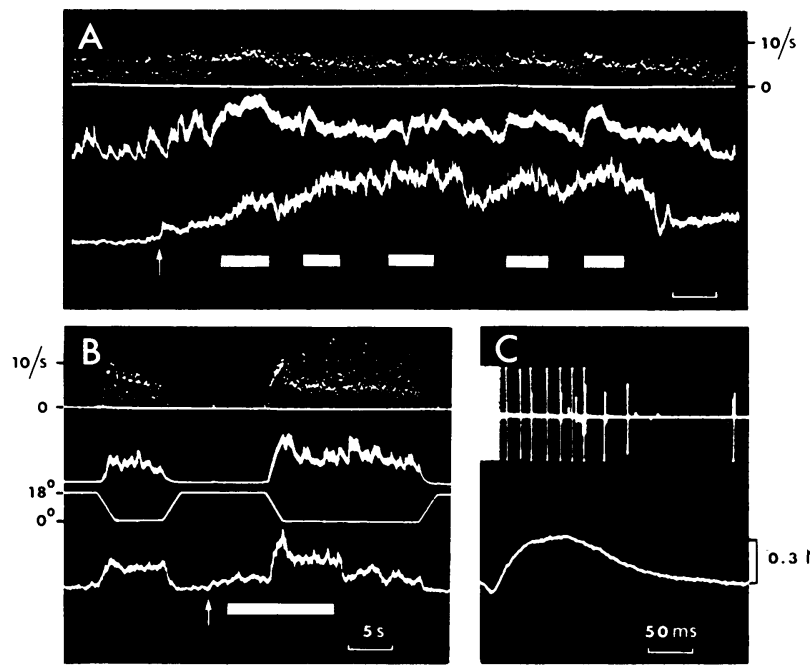

$0.3 \mathrm{Nm}$

with the request to prepare for the manoeuvre (indicated by arrow). C: unit identification using an electricallyinduced muscle twitch. Fibre discharges during the rising phase and plateau of the twitch. Note that the stimulus was delivered through the microelectrode, which was then switched for recording (blocking time approximately. $10 \mathrm{~ms}$ ). Upper trace: neurogram; lower trace: torque.

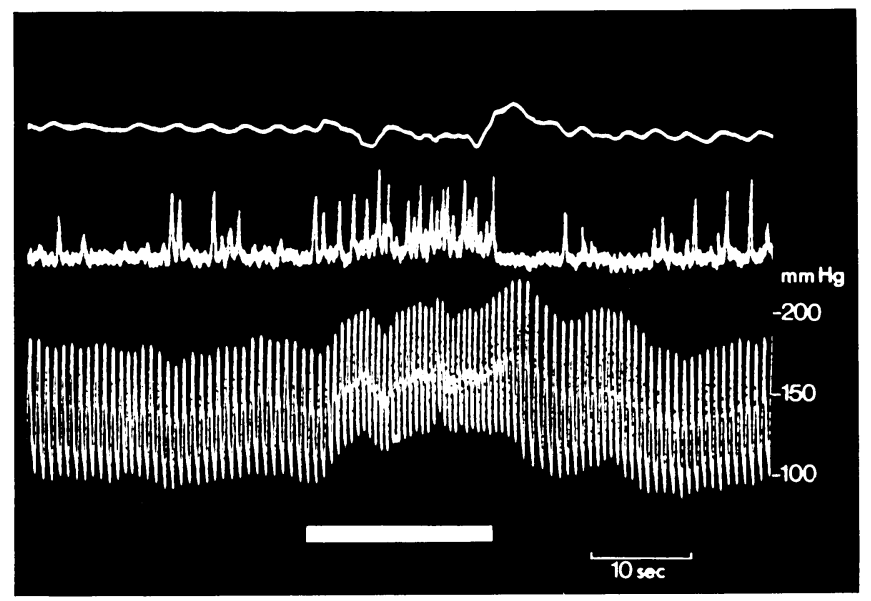

FIG. 8 Increase in sympathetic efferent activity induced by reinforcement manoeuvre. Muscle nerve sympathetic outflow in a peroneal muscle nerve fascicle shown as integrated neural activity (middle trace), in a mildly hypertensive subject. Upper trace: respiratory movements; lower trace: intraarterial blood pressure. Reinforcement consisted of forceful clenching of one fist (indicated by the solid bar) and is associated with changes in respiratory rhythm and blood pressure. The previously scanty pulse synchronous neural discharges become prominent during the manoeuvre. ing from body displacement or contraction of synergistic or antagonistic muscles. In Fig. 4 discharge frequency is positively correlated with the mechanical events as seen in the torque recording. In different manoeuvres the discharge frequency of this fibre increased, decreased or did not alter, largely parallelling the extent and direction of the change in torque.
EFFECTS OF REINFORCEMENT ON MULTIUNIT INTRAFASCICULAR RECORDINGS Since data obtained from single afferent nerve fibres may be biased by sampling errors, the effects of reinforcement manoeuvres were also studied in multiunit intrafascicular recordings-which are largely dominated by Ia afferent fibres (Hagbarth and Vallbo. 1968; Wallin et al., 1973). Provided the subject 
remained relaxed, no evidence of increased neural activity attributable to the manoeuvres was seen, whether the appropriate muscle was at constant length or being subjected to controlled passive stretch. In Fig. 5 the lack of effect of reinforcement on integrated neural activity is shown during passive stretching at fast rates (A) and relatively slow rates (B).

In Fig. 6 percussion of the Achilles tendon elicited an afferent neural discharge and a reflex contraction of the triceps surae. The reinforcement manoeuvre performed in B produced increases in reflex torque and reflex EMG but no increase in size of the afferent neural volley. This particular intrafascicular recording site was dominated by discharges in a relatively small number of fibres, and with careful filtering the discharges of a single Ia afferent fibre could be discriminated. The reinforcement manoeuvre also failed to affect the response of this fibre to tendon percussion, although, as may be expected, a greater discharge was seen during the relaxation phase of the enhanced reflex contractions.

EFFECTS OF REINFORCEMENT ON FIBRES OF NONSPINDLE ORIGIN Occasionally neural activity other than that of muscle spindle origin was seen to be modified during the performance of a Jendrassik manoeuvre. Figure 7 illustrates potentials of a group Ib afferent fibre from a Golgi tendon organ in the flexor digitorum profundus muscle. During the reinforcement, the subject unintentionally tensed the forearm muscles, thus producing a greater discharge frequency of the Ib afferent fibre.

It has long been recognized that muscle work produces vasoconstriction in resting muscles. In a number of intrafascicular recording sites pulsesynchronous sympathetic vasoconstrictor activity was seen, at times obscuring the afferent potentials. Figure 8 illustrates how fist clenching causes a marked enhancement of the sympathetic efferent activity recorded in a peroneal muscle nerve fascicle of a subject with mild hypertension. In some of the most forceful Jendrassik manoeuvres performed in the present study the subjects sometimes held their breath and made an expiratory effort against closed glottis as in the Valsalva manoeuvre. As described in full elsewhere (Delius et al., 1972) and confirmed in the present study, this type of manoeuvre is particularly potent in enhancing the sympathetic pulse synchronous outflow to the muscles.

\section{DISCUSSION}

It has been suggested previously that 'there is a marked increase of muscle spindle activity in a relaxed muscle during contraction of a remote muscle' (Burg et al., 1974) and that this fusimotor sensitization of the end organs contributes to the reflex reinforcement produced by the Jendrassik manoeuvre. It has been further suggested that such effects are mediated at least in part by selective activation of dynamic fusimotor fibres (Szumski et al., 1974). With careful monitoring of the state of the extrafusal muscle, the present study has been unable to confirm these assertions. Any change in spindle activity was always accompanied by EMG or torque changes involving the extrafusal muscle. Using different means of testing the position-and velocity sensitivity of spindles, effects attributable to selective activation of static or dynamic fusimotor fibres have been sought, but without success.

Were reinforcement manoeuvres capable of selectively activating muscle spindles, then such manoeuvres could conceivably be used in future studies as a means of identification of a spindle. In the present study, however, only $50 \%$ of the spindles tested altered discharge frequency during reinforcement manoeuvres, and in most of these the effects were variable, a decrease in frequency being occasionally recorded. Furthermore, neural activity of other than spindle origin was seen to be affected by reinforcement manoeuvres. Thus it is clear that a change in firing frequency in response to the Jendrassik manoeuvre is not a specific characteristic of muscle spindles, and this criterion cannot be used as a means of identification of spindles.

Marked changes in sympathetic vasoconstrictor outflow to the muscles may accompany reinforcement manoeuvres. Indeed, in some intrafascicular recording sites the pulse synchronous sympathetic bursts have obscured the afferent activity primarily under study. Sympathetic stimulation is capable of modifying spindle function in the cat (Hunt, 1960) and in 
man it has been suggested that adrenaline 'sensitizes' muscle spindles, thus aggravating spontaneous tremor and increasing the spindle response to vibration (Hodgson et al., 1969). However, the occurrence of profound changes in sympathetic outflow unaccompanied by changes in muscle spindle activity, as seen in this and earlier studies, provides evidence that the physiological effects of the sympathetic nervous system on spindle function in man are negligible.

MECHANISMS OF REFLEX REINFORCEMENT In relaxed muscles no evidence of increased dynamic spindle sensitivity has been found to accompany tendon jerk reinforcement. As suggested in Fig. 6 , the reflex enhancement noted during such contractions is due, not to a greater afferent input, but to altered processing of the afferent volley within the cord ( $c f$. Clare and Landau, 1964).

Other mechanisms could, however, contribute to reflex reinforcement. Wartenberg (1953) has advocated that a deliberate weak contraction of the muscle to be tested is the best method of reflex reinforcement. The present study suggests that few untrained persons would be able to relax completely in all distant muscles when being encouraged to perform a forceful Jendrassik manoeuvre. Therefore, many clinical reinforcement tests are probably associated with unintentional contractions in the muscle to be tested. We have observed that weak voluntary contractions may be accompanied not only by increased static spindle firing but also by increased dynamic spindle responses to tendon percussion (unpublished observations). This, however, should not be taken as conclusive evidence of an increased dynamic fusimotor influence. Any contraction alters the mechanical state of the muscle and it is conceivable that an increased afferent percussion discharge is simply a reflection of a more effective transmission of the tendon percussion wave to the spindle receptors.

PRINCIPLE OF ALPHA-GAMMA COACTIVATION The significance of the present results extends beyond the mere Jendrassik manoeuvre. The findings of Burg et al. (1974) implied an exception to the principle of alpha-gamma coactivation in motor control. This principle was established for human motor acts by studies of isometric and isotonic voluntary contractions (Hagbarth and Vallbo, 1968; Vallbo, 1970b, 1971, 1972, 1974). More recently, the principle has been shown to apply to rapid alternating movements (Hagbarth et al., 1975a) and the involuntary tremulous movements of patients with Parkinson's disease (Hagbarth et al., 1975b). In the present study, evidence has been presented that the unintentional postural adjustments and 'associated' movements that may accompany the performance of a consciously directed motor act are also carried out according to the principle of alpha-gamma coactivation. Although animal experiments have shown that differential effects on the skeletomotor and fusimotor systems can occur in conditioned movements (Buchwald and Eldred, 1962) and can be induced by stimulation of different regions of the cortex, basal ganglia, and brain stem, the significance of these findings to the normal control of movements, particularly in man, is conjectural. Thus far, the recordings of spindle afferent activity in awake human subjects have provided increasing evidence that the supraspinal influences which control movement and posture are directed to the skeletomotor and fusimotor systems in parallel. To date, the segmental phasic stretch reflex represents the only documented exception to the principle of alpha-gamma coactivation (Burg et al., 1973, 1974; Hagbarth et al., 1975b).

\section{REFERENCES}

Buchwald, J. S., and Eldred, E. (1962). Activity in musclespindle circuits during learning. In Symposium on Muscle Receptors, pp. 175-183. Edited by D. Barker. Hong Kong University Press: Hong Kong.

Burg, D., Szumski, A. J., Struppler, A., and Velho, F. (1973). Afferent and efferent activation of human muscle receptors involved in reflex and voluntary contraction. Experimental Neurology, 41, 754-768.

Burg, D., Szumski, A. J., Struppler, A., and Velho, F. (1974). Assessment of fusimotor contribution to reflex reinforcement in humans. Journal of Neurology, Neurosurgery, and Psychiatry, 37, 1012-1021.

Clare, M. H., and Landau, W. M. (1964). Fusimotor function. Part 5. Reflex reinforcement under fusimotor block in normal subjects. Archives of Neurology (Chic.), 10, 123-127.

Delius, W., Hagbarth, K-E., Hongell, A., and Wallin, B. G. (1972). Manoeuvres affecting sympathetic outflow in human muscle nerves. Acta Physiologica Scandinavica, 84, 82-94.

Green, D. G. (1967). A transistor instantaneous frequency meter. Medical and Biological Engineering, 5. 387-390. 
Hagbarth, K-E., Hongell, A., Hallin, R. G., and Torebjörk, H. E. (1970a). Afferent impulses in median nerve fascicles evoked by tactile stimuli of the human hand. Brain Research, 24, 423-442.

Hagbarth, K-E., Hongell, A., and Wallin, B. G. (1970b). The effect of gamma fibre block on afferent muscle nerve activity during voluntary contractions. Acta Physiologica Scandinavica, 79, 27A-28A.

Hagbarth, K-E., and Vallbo, Å. B. (1968). Discharge characteristics of human muscle afferents during muscle stretch and contraction. Experimental Neurology, 22, 674-694.

Hagbarth, K-E., Wallin, G., and Löfstedt, L. (1975a). Muscle spindle activity in man during voluntary fast alternating movements. Journal of Neurology, Neurosurgery, and Psychiatry, 38, 625-635.

Hagbarth, K-E., Wallin, G., Löfstedt, L., and Aquilonius, S-M. (1975b). Muscle spindle activity in alternating tremor of Parkinsonism and in clonus. Journal of Neurology, Neurosurgery, and Psychiatry, 38, 636-641.

Hodgson, H. J. F., Marsden, C. D., and Meadows, J. C. (1969). The effect of adrenaline on the response to muscle vibration in man. Journal of Physiology, 202, 98-99P.

Hunt, C. C. (1960). The effect of sympathetic stimulation on mammalian muscle spindles. Journal of Physiology, 151, 332-341.

Szumski, A. J., Burg, D., Struppler, A., and Velho, F. (1974). Activity of muscle spindles during muscle twitch and clonus in normal and spastic human subjects. Electroencephalography and Clinical Neurophysiology, 37, 589-597.

Vallbo, \&. B. (1970a). Slowly adapting muscle receptors in man. Acta Physiologica Scandinavica, 78, 315-333.

Vallbo, A. B. (1970b). Discharge pattern in human muscle spindle afferents during isometric voluntary contractions. Acta Physiologica Scandinavica, 80, 552-566.

Vallbo, $\AA$. B. (1971). Muscle spindle response at the onset of isometric voluntary contractions in man. Journal of Physiology, 218, 405-431.

Vallbo, \&. B. (1972). Single unit recordings from human peripheral nerves: muscle receptor discharge in resting muscles and during voluntary contractions. In Neurophysiology studied in Man, pp. 281-295. Edited by G. G. Somjen. Excerpta Medica: Amsterdam.

Vallbo, Å. B. (1974). Human muscle spindle discharge during isometric voluntary contractions. Amplitude relations between spindle frequency and torque. Acta Physiologica Scandinavica, 90, 319-336.

Wallin, B. G., Hongell, A., and Hagbarth, K-E. (1973). Recordings from muscle afferents in Parkinsonian rigidity. In New Developments in EMG and Clinical Neurophysiology, vol. 3, pp. 263-272. Edited by J. E. Desmedt. Karger: Basel.

Wartenberg, R. (1953). Diagnostic Tests in Clinical Neurology, pp. 119-120. Year Book Publishers: Chicago. 